\title{
Reestruturação produtiva e condições de trabalho: Percepções dos trabalhadores
}

\author{
Maria Rosa Lombardi*
}

\begin{abstract}
RESUMO: Após a introdução de modificações no sistema produtivo e na forma de gestão pessoal implementada nas três empresas de autopeças pesquisadas, os trabalhadores avaliam que houveram ganhos, mas, também, que passaram a estar sujeitos a maiores pressões mentais e físicas. Os ganhos provêm, principalmente, da introdução de inovações tecnológicas que tornaram o trabalho mais leve e fácil. $O$ aumento das pressões derivam da intensificação do ritmo de trabalho, que tem aumentado os casos de LER, e da operalização da questão da multifuncionalidade. Homens e mulheres avaliaram diferentemente os efeitos da multifuncionalidade no seu trabalho na fábrica. É possível que, quando as mulheres afirmam que "nada mudou" no seu trabalho após a introdução da multifuncionalidade, elas estejam tomando como referência o espaço doméstico, onde lhes é "natural" o desempenho de múltiplas tarefas, às quais sempre podem ser acrescentadas mais algumas.
\end{abstract}

Palavras-chave:Reestruturação produtiva, setor automotivo, condições de trabalho, relações de gênero

Reestruturação produtiva:

Objetivos semelhantes, variadas formas de atingi-los

No último quarto de século estamos assistindo a uma série de mudanças nos contextos econômico, político, social e cultural, em ní-

* Socióloga, mestranda da Faculdade de Educação da Unicamp. 
vel mundial, as quais têm sido amplamente discutidas. Desde meados dos anos 60 e início dos 70, nos países centrais, acumulavam-se indícios que sinalizavam em direção a um novo período de crise, movimento de caráter cíclico, dentro do modo de produção capitalista (Harvey 1996). Entre esses indícios estavam a existência de capacidade ociosa no setor produtivo, particularmente, na indústria, um excesso de mercadorias e estoques, queda na produtividade e na lucratividade corporativas, acirradas pela intensificação da competição internacional e pelos efeitos da crise do petróleo, em 1973, e a presença de grandes excedentes de capital. O longo período de expansão do pós-guerra, o qual teve como base um conjunto de práticas de controle do trabalho, tecnologias, hábitos de consumo e configurações específicas de poder político-econômico, interrompe-se, iniciando-se uma época de rápidas mudanças, fluidez e incerteza. É nesse contexto que começaram a surgir, como opção à crise, indícios de um novo regime de produção capitalista estendendo as bases para uma acumulação de maior proporção, em escala global.

Esse novo regime, denominado por muitos de "acumulação flexível", se basearia numa recombinação particular de utilização das estratégias de mais-valia absoluta e relativa. Sumarizando o pensamento de Harvey, a estratégia de mais-valia absoluta tem sido posta em prática através da imposição de mais horas de trabalho aliada à redução dos salários reais e ao conseqüente rebaixamento do padrão de vida, por meio da transferência do capital corporativo de regiões de altos salários para outras de baixos salários, criando-se o "fordismo periférico". No intuito de aumentar a mais-valia relativa, vêm sendo implementadas profundas mudanças de ordem organizacional e tecnológica. Essas mudanças promoveram cortes de empregos, de forma generalizada em todos os setores econômicos, para gerar lucros temporários para firmas inovadoras e lucros mais generalizados com a redução dos custos dos bens que definem o padrão de vida do trabalho.

Ambos os processos vêm acontecendo em nível mundial, adotando combinações diversas, resultando em configurações diferenciadas. A repetição de estudos e pesquisas sobre a reestrutração produtiva no setor industrial, orientados por diferentes interpretações teóricas e realizados em variados espaços geográficos, tem contribuído para algumas constatações importantes.

Em primeiro lugar, a implementação de novas tecnologias de produção e de novos desenhos organizacionais para a gestão do tra- 
balho, de fato, ocorreu em determinados países, em certas empresas (transnacionais, particularmente), em determinados ramos econômicos, mas não assumiu um caráter generalizado, muito pelo contrário, continuou a conviver - temporal e espacialmente - com: a) a tradicional forma de produção em massa, com baixo conteúdo tecnológico e utilização intensiva de mão-de-obra de baixa qualificação, realizando trabalho parcelizado e rotineiro e, b) com sistemas de trabalho doméstico, familiar, paternalista, os quais se pensava terem desaparecido completamente com a evolução do capitalismo.

Em segundo lugar, as alternativas de combinação entre novas tecnologias e novos desenhos organizacionais assumidas por empresas, geralmente de setores mais modernos, em diferentes países dependeram, intrinsecamente, de uma série de condições particulares a esses países e a essas empresas, tais como: a) o tipo de mercado de trabalho e de sistema de formação profissional neles existentes; b) a organização de seu tecido industrial; c) as condições econômico-sociais peculiares ao país no momento de introdução daquelas modificações e, d) a tradição de organização dos trabalhadores e sua capacidade de influir nos rumos do processo de reestruturação em curso.

Terceiro, num mesmo país, apresentam-se e convivem diversas estratégias de produção e organização do trabalho, dependendo, entre outros fatores, da região geográfica, do ramo industrial, do porte das empresas, da posição ocupada pelas empresas na cadeia produtiva. Em quarto lugar, diferentes estratégias de produção e organização do trabalho podem coexistir, lado a lado, numa mesma empresa; por exemplo, a manutenção das tradicionais linhas de montagem junto a células de produção.

Finalmente, os diversos modelos de organizar a produção e o trabalho, gerados ao redor do mundo, foram captados em determinado momento do tempo onde vigiam certas condições econômicas e sociais e estão sujeitos a adaptações, mesmo em seus países de origem, para continuarem sobrevivendo quando aquelas condições se alteram.

Exemplos já clássicos das diversas formas que a reorganização da produção e do trabalho pode assumir regionalmente são o chamado "modelo japonês" de produção, a configuração de empresas em clusters ou "distritos industriais" - dentre os quais a "Terceira Itália" é um dos exemplos mais citados -, os sistemas de co-determinação sueco e alemão, funcionando de forma acoplada à produção em massa. 
Segundo Hirata (1993), o termo "modelo japonês" vem sendo utilizado em várias acepções, quais sejam:

- um modelo de relações industriais que teria como característica principal a exclusão de grande parcela de trabalhadores, pois se trata do sistema de emprego denominado "vitalício", adotado por grandes empresas japonesas para os empregados com contratos regulares e do sexo masculino;

- um modelo de organização do trabalho e da empresa que diria respeito a uma modalidade particular de divisão social do trabalho na empresa, com a não-alocação do trabalhador a um posto de trabaIho específico, o que geraria diversas conseqüências. A primeira delas refere-se a um funcionamento baseado na polivalência e na rotação de tarefas. Outros desdobramentos da adoção da nova organização do trabalho seriam uma divisão menos nítida entre operários de manutenção e de fabricação e entre as diversas categorias hierárquicas e uma linha de demarcação mais difusa entre a direção e a execução, com o trabaIhador dominando o processo global de produção. Além disso, a organização do trabalho à japonesa compreende - e aqui repousa um de seus aspectos mais visíveis e difundidos - a implantação de um conjunto de técnicas e métodos de organização do trabalho e da produção, como o JIT (Just In Time), o CCQ (Círculo de Controle de Qualidade), a célula de produção, o trabalho em grupo etc.;

- um modelo de organização industrial entre empresas com característica dualista e hierarquizante, no qual se estabelecem trocas de tipo muito particular entre fornecedores e subcontratados de um lado e as grandes empresas, de outro.

Reynaud (1993) lembra que o conjunto dessas práticas foi sendo criado pelas empresas japonesas, não de uma só vez, mas sucessivamente, após a Segunda Guerra Mundial, a partir de materiais heterogêneos como uma legislação social importada por Mac Arthur, recursos de cooperação oferecidos pela cultura nacional, possibilidades disponibilizadas pela tecnologia na segunda metade do século $X X$, características específicas dos mercados consumidor e de trabalho japonês logo após o final da guerra.

Entretanto, o processo continua em andamento e o quadro dos anos 90 não é o mesmo que deslumbrou o mundo ocidental nos anos 70 ou 80 . Posthuma (1995) assinala que as práticas japonesas, perfeitamente adequadas a um contexto econômico de crescimento, têm 
se alterado com a recessão e o declínio na demanda por carros. Por exemplo, em função de congestionamentos de tráfego e da poluição ambiental decorrente, as montadoras japonesas estão deixando acumular algum estoque, em substituição à entrega de peças em JIT (Just In Time) para a linha de montagem, em pequenos lotes, várias vezes ao dia. Além disso, devido às pressões de custo, o processo de desenvolver, projetar e fabricar novos modelos constantemente tem apresentado sinais de arrefecimento, ou seja, vem diminuindo a proliferação de modelos de carros. A relação entre a empresa cliente e as suas fornecedoras também parece estar passando por mudanças, pois as grandes montadoras japonesas estão reduzindo o número de fornecedores de $1^{a}$. linha e, o mais espetacular, estão insistindo para que esses fornecedores tornem-se menos dependentes delas.

Outro modelo de organização da produção e do trabalho muito comentado é o que assume a forma de distritos industriais. Essas experiências, que não foram induzidas, mas tiveram sua origem espontaneamente e se desenvolveram durante várias décadas até atingirem o estágio atual, adotaram o "caminho alto" de cooperação entre firmas, onde é relevante a cooperação mútua quanto ao crédito, à adoção de inovações como fator de competitividade e ao investimento na qualificação da mão-de-obra. Nelas, também, o governo local e outras instituições públicas e privadas tiveram importante papel, tanto no tocante à obediência das leis trabalhistas, como no amparo ao desenvolvimento de novas tecnologias, na busca de novos mercados, no treinamento de engenheiros e trabalhadores e no levantamento do capital necessário aos empreendimentos locais. Schmitz e Musyck (1993) ressaltam oito atributos característicos de um distrito industrial. O primeiro deles seria a proximidade geográfica entre empresas; o segundo, a especialização setorial; o terceiro, a predominância de pequenas e médias empresas. Os demais atributos identificadores de um distrito industrial são a colaboração próxima entre firmas, a competição baseada mais em inovações do que em baixos salários, a identidade sóciocultural, o que facilita a relação entre firmas e empregados qualificados, a presença de organizações ativas de auto-ajuda e, finalmente, a existência de governos municipais e regionais ativos, o que impulsionou e fortaleceu a capacidade inovadora das indústrias locais.

Os casos mais famosos de distritos industriais bem-sucedidos são europeus, como os da região da Emilia-Romagna ou Terceira Itália, de Jutland na Dinamarca, de Baden-Wuttemberg na Alemanha e 
do sudoeste de Flandres. Entretanto, como salienta Brusco (1982) a respeito da Emilia-Romagna - o que, em alguma medida, poderia ser estendido aos demais distritos industriais europeus -, o ponto fraco do modelo está na manutenção da capacidade de inovação e de flexibilidade de forma constante por parte dos empresários, pois é essa característica que lhes dá condições de competir no mercado e azeitar toda a engrenagem produtiva regional.

O que se convencionou chamar de modelo "sueco" de produção em massa se originou de experiências desenvolvidas em vários setores industriais daquele país, a partir dos anos 70, no âmbito da organização do trabalho.

A Suécia conta com um mercado de trabalho fechado - onde o desemprego é praticamente inexistente - e com uma mão-de-obra altamente qualificada, detentora de altos índices de sindicalização : mais de $80 \%$ dos empregados são sindicalizados. Para uma mão-de-obra com essas características, os trabalhos rotineiros e repetitivos, destituídos de conteúdo, desenvolvidos nas linhas de montagem de automóveis, eram profundamente desestimulantes, causando altas taxas de absenteísmo voluntário e queda na produtividade das empresas.

O modelo "sueco" foi desenvolvido a fim de se tornar uma alternativa de organização do trabalho, em função de especificidades locais. Caracteriza-se " pela ênfase no trabalho em grupo, pela participação dos sindicatos e dos trabalhadores em diversos aspectos da organização da produção, por tentativas de criar ambientes de trabaIho onde o homem possa interferir e participar de maneira muito mais ampla do que em ambientes influenciados pelo padrão clássico taylorista-fordista" (Marx, 1994).

As experiências mais conhecidas de implantação desse modelo são as que tiveram lugar na indústria automobilística sueca, em duas plantas da Volvo: Kalmar e Udevalla.

Na planta de Kalmar - ao contrário do que aconteceu em Udevalla -, o conceito de trabalho em linha de montagem, cujo ritmo é controlado externamente aos trabalhadores, não chegou a ser totalmente abandonado. Foram introduzidas diversas alterações na organização do trabalho, entre as quais estão o desdobramento da montagem por várias unidades físicas (modularização), a introdução de mini-linhas em que o trabalho era enriquecido e desenvolvido de for- 
ma semi-autônoma em cada uma delas, a redução dos níveis hierárquicos e das diferenças salariais, tanto entre os próprios trabalhadores, como entre eles e as gerências.

Foi, porém, na planta de Udevalla onde se deu a tentativa mais radical de rompimento com os moldes tradicionais vigentes de organização do trabalho. Essa experiência que ficou conhecida como produção em "docas", trouxe, segundo Berggren (1994), quatro principais contribuições para a renovação da produção e do trabalho, a saber: 1) a integração do trabalho fragmentado, característico da produção em massa, em um modo de operação mais sistêmico. Em vez de uma longa linha de montagem, foram constituídos 14 pequenos grupos semi-autônomos que construíam carros completos com o objetivo de criar alternativas às estruturas de trabalho confinado e repetitivo. Essas alternativas eram socialmente desejáveis porque resultaram em um enriquecimento qualitativo do trabalho e na redução das cargas de trabalho físico; 2) o desenvolvimento compreensivo da ergonomia do trabalho manual. Em Udevalla esse esforço esteve muito relacionado à presença de grande proporção de mulheres $(40 \%$ dos trabalhadores) e à necessidade de adaptar ferramentas e métodos às diferenças humanas; 3) os esforços para transformar os sistemas de trabalho no sentido de menor rigidez e maior adaptabilidade às diversas necessidades humanas. Isso foi resposta a um mercado de trabalho muito organizado, com um grande número de mulheres trabalhadoras e, praticamente, nenhum desemprego; 4) a convivência com um alto grau de envolvimento sindical na tomada de decisões e nos processos de planejamento, encarando os trabalhadores como parceiros independentes, com seus próprios interesses legítimos.

Ainda que as plantas de Kalmar e Udevalla tenham sido fechadas no início dos anos 90, a utilização dos princípios da produção em docas continua a ocorrer na Suécia e, fora dela, aqueles princípios vêm despertando o interesse de outras empresas em todo o mundo. Berggren acredita que ambientes com altas taxas de desemprego, grandes diferenças de renda, proteção social deficiente e baixos padrões de qualificação da força de trabalho facilitariam a adoção das características regressivas da produção enxuta. Por outro lado, políticas industriais de mercado avançadas, seguridade social compreensiva, poderiam causar problemas de competitividade no curto prazo, mas, poderiam, no longo prazo, estimular inovações, aperfeiçoamentos e soluções sustentáveis. 
Também o sistema alemão se baseou, segundo Jurgens (1995), num círculo virtuoso de características de mercado, mão-de-obra qualificada e co-determinação. Por produzirem para as camadas mais abastadas do mercado, as indústrias alemãs, particularmente a automotiva, puderam mitigar as pressões para reduzir custos, pagar salários que se aproximavam das demandas dos sindicatos e produzir produtos de alta qualidade, em condições de trabalho que aproveitaram as plenas vantagens de uma mão-de-obra altamente qualificada.

Altos salários, boas condições de trabalho e co-determinação são elementos integrantes do modelo alemão, o qual nasceu nos anos $50 \mathrm{e}$ se desenvolveu como uma das instituições centrais da Alemanha democrática do pós-guerra. Esse modelo visava regular o relacionamento entre capital e trabalho, estruturando-se em níveis decisórios, desde o chão da fábrica até os fóruns nacionais entre os sindicatos de empregados e as associações de empregadores. Seus princípios foram - e ainda são amplamente aceitos pelos principais atores sociais alemães. O sistema de co-determinação é baseado, primariamente, em políticas governamentais e é suficientemente independente de plataformas partidárias e alianças políticas. Prova disso foi a manutenção desse sistema durante os governos conservadores. O trabalhador qualificado é considerado a "peça-chave" na fábrica modernizada e tem sido amplamente sustentado que as estruturas high-tech de trabalho dariam impulsos competitivos à Alemanha, mesmo nos segmentos de produção em massa.

Nos ano 90, o conceito da produção enxuta tem encontrado cada vez mais adeptos na Alemanha, trazendo ameaças ao sistema de codeterminação. Jurgens acredita que o verdadeiro teste desse sistema ainda está por vir, na medida em que se intensifique a competição na Europa.

\section{Adaptando as técnicas japonesas}

na indústria automobilística brasileira

Tem ficado cada vez mais claro que, em qualquer lugar do mundo, não existe um único modelo possível para resolver a crise de competitividade das empresas industriais. A adoção de um elemento de determinado modelo ou de um conjunto de práticas adquire seu sentido também a partir do contexto em que são introduzidos, da conjuntura econômica, das conquistas provenientes de práticas anteriores. 
No Brasil, como em muitos outros países do mundo, o ideal da "produção enxuta" causou funda impressão e, num primeiro momento, o excepcional desempenho das indústrias japonesas foi atribuído, em grande medida, a algumas das práticas inovadoras de organização e gestão da produção por elas adotadas. O fato de essas práticas poderem ser implementadas sem grandes investimentos de capital foi um bom incentivo para sua experimentação e, com a adoção de parte dessas práticas, a indústria automobilística nacional tem procurado "obter flexibilidade e integração nas fábricas, alcançar padrões mais elevados de qualidade e produtividade e, como decorrência, maior competitividade nos mercados interno e externo" (Bresciani 1997, pp. 65).

Salerno (1993) constatou - já nos primeiros anos da década de 1980 - que a extensão da introdução das técnicas japonesas no Brasil ainda era parcial e seletiva. O JIT externo era aplicado a poucos fornecedores, notadamente da indústria automobilística, enquanto que o JIT interno teve razoável implantação, embora fosse comum as empresas utilizarem sistemas semelhantes ao Kanban, mas não trabalharem o JIT. Já os CCQs sofreram, na sua implantação, influências das flutuações da economia e do combate sindical. Quanto às células de produção, sua presença foi notada num nível razoável nos setores de produção seriada de média e alta escalas. O autor considera que a implantação daquelas técnicas tem sido "conservadora" na medida em que o trabalho real continua tendo uma prescrição individual via roteiros de fabricação etc. e a "polivalência" parece ter sido entendida como multitarefa; os grupos semi-autônomos estão ausentes nas empresas com células; os CCQs foram usados numa perspectiva de modernização conservadora, na medida em que os manuais apontam os absurdos do taylorismo, mas o trabalho real continua taylorizado e ocorreu uma forte intensificação do trabalho, concomitantemente com a implantação de células e JIT interno.

Ainda que uma série de mudanças venham se consolidando na organização do trabalho no complexo automotivo brasileiro, associadas às práticas mencionadas acima, tradicionais práticas tayloristas/ fordistas como, por exemplo, padronização intensa do trabalho, medições de tempos e estudos de movimentos, linhas de montagem tradicionais continuam em vigor, coexistindo com os JIT interno e externo, o Kanban, as células de produção e outras técnicas de inspiração japonesa (Bresciani 1997). 
Neste tópico procuramos sistematizar as percepções de trabalhadores sobre as alterações verificadas no trabalho cotidiano, em função da introdução de inovações produtivas e organizacionais nas empresas onde trabalhavam. Trata-se, aqui, de três empresas de autopeças, sendo uma delas do ramo eletroeletrônico, uma do plástico e outra do ramo mecânico, situadas na região da Grande São Paulo. ${ }^{1}$ Essas empresas, embora em estágios diversos, encontram-se em processo de reorganização de seus sistemas produtivo e organizacional. Todas obtiveram certificações de qualidade ISO e, em diferentes graus de disseminação, nelas estão presentes o CEP, o JIT externo, principalmente, o JIT interno e o Kanban, as células de produção, os CCQs.

Foram realizadas dez entrevistas, oito com moças e duas com rapazes. Todos os entrevistados trabalhavam nas empresas há tempo suficiente para ter condições de comparar como era seu trabalho antes e depois das modificações introduzidas. Das oito moças entrevistadas, cinco trabalhavam em seções de montagem e três eram operadoras de máquina. Um dos rapazes era fresador-ferramenteiro e o outro, prensista em uma seção de estamparia na indústria mecânica. Dentre as informações obtidas, elegemos como dimensões de interesse para o presente trabalho:

- as alterações concretas nas tarefas executadas: grau de responsabilidade e ritmo;

- as mudanças organizacionais e a comunicação;

- a questão da multifuncionalidade e

- $\quad$ as condições de trabalho.

Ao darmos voz aos sujeitos para que expressem suas percepções e representações sobre as relações que vivem no trabalho, estamos pressupondo que homens e mulheres, além de terem posicionamento diferenciado dentro do mercado de trabalho industrial (quanto a ocupações desempenhadas, remuneração etc.), também são portadores de concepções, de percepções diversas, porque perpassadas pelas relações de gênero que, no mundo do trabalho, encontram apenas mais uma oportunidade de se manifestarem. Isso porque, conforme explica Souza-Lobo (1991, p. 191), "a problemática de gênero se coloca como uma relação social que atravessa a história e o tecido social, as instituições e as mentalidades, objeto 
interdisciplinar por excelência, ao mesmo tempo, do domínio das teorias sobre as famílias, mercado e processo de trabalho, cidadania, partido político e movimentos sociais, tanto quanto da subjetividade".

O pequeno número de entrevistas disponíveis onde há predominância de entrevistadas do sexo feminino, entretanto, nos permitiu obter apenas indícios esparsos dessa subjetividade sexualizada, a partir dos quais ressaltaremos as diferenças de percepções entre homens e mulheres apenas quando elas se mostrarem suficientemente explícitas. Alguns dos indícios encontrados sinalizam a necessidade de maior aprofundamento e detalhamento, a partir de um maior número de casos. Nesse sentido, algumas conclusões desta análise devem ser encaradas menos como resultados definitivos e mais como hipóteses a serem postas em prova futuramente.

As alterações concretas nas tarefas executadas

Após a introdução das mudanças nas empresas pesquisadas, a natureza do trabalho das moças manteve-se, uma vez que a maior parte delas permaneceu nos seus postos de trabalho, em linhas de montagem. Se a natureza do trabalho - montagem de pequenas peças e componentes não se alterou, ocorreram, sim, modificações no trabalho. Algumas moças passaram a realizar, com o auxílio de máquinas (em geral pequenas prensas), as tarefas que antes eram executadas manualmente. Uma dessas muIheres, que trabalhava na indústria mecânica, também passou a controlar a máquina pneumática que agora opera, vai constantemente ao setor de desenhos para confirmar o desenho do produto, preenche cartão sobre o andamento da montagem de válvulas.

Outras acrescentaram às tarefas manuais, a operação de máquinas atualmente instaladas nas linhas de montagem Algumas das entrevistadas que já operavam máquinas anteriormente, também tiveram sua rotina de operação alterada, em função da instalação de dispositivos nessas máquinas que, na sua opinião, tornaram o trabalho menos pesado, mais fácil, uma vez que, em muitos casos, deixaram de apertar pedais ou botões e passaram a acionar sensores eletrônicos com leve toque dos dedos:

- Antes apertava botões e era cansativo. Hoje há máquinas melhores, não precisa apertar botões e o trabalho vem semipronto. 
- Antes a prensa era acionada a pedal, era perigosa... hoje, o controle é por sensor, acionado pelo toque das mãos.

Em outro caso, foi conectado um alimentador automático na máquina, evitando que a trabalhadora carregasse caixas com partes de peças a serem montadas ou trabalhadas, tornando o trabalho menos pesado, mas também mais rápido:

- Hoje a máquina tem alimentador automático, fico só observando a máquina de encamisar pistões.

Em dois casos, houve mudança efetiva de posto de trabalho. Uma das moças mudou de posição na linha de montagem porque adquiriu LER: ao invés de proceder à montagem manual no correr da linha, passou para o fim dela, testando os produtos, além de fazer outras tarefas em vários outros lugares da fábrica. A outra mulher passou de montadora para operadora de máquinas porque não se adaptou ao ritmo mais rápido da colega com a qual formava uma dupla.

Os dois entrevistados do sexo masculino viveram situações diferentes após a introdução de mudanças na organização do trabalho. $O$ fresador-ferramenteiro da indústria eletroeletrônica deixou de construir ferramentas porque parte da ferramentaria foi terceirizada, enquanto o prensista da indústria mecânica, ao contrário, acrescentou ao seu trabaIho outras tarefas como preparar a máquina, fazer manutenção preventiva, inspecionar a qualidade dos produtos que fabrica.

Grau de responsabilidade e ritmo de trabalho

A quase totalidade dos entrevistados sente que seu grau de responsabilidade aumentou após a introdução de mudanças no sistema de produção e na organização do trabalho. O aumento da responsabilidade do trabalhador sobre seu próprio trabalho é incentivado por técnicas de autocontrole como o CEP e de controle grupal, os CCQs, por exemplo, bem como pela aceleração do ritmo.

O ritmo de trabalho exige maior atenção e vigilância porque há um maior número de operações a realizar e/ou porque o trabalho dos companheiros dispensados foi redistribuído entre os que permaneceram na empresa: 
- Tem que ter mais qualidade... fazer uma checagem visual (do produto), verificar peças e marcar no cartão de CEP e produzir.

- Hoje a responsabilidade aumentou um pouco, devido à rapidez da produção.

- Hoje somos só quatro e temos que fazer muitas coisas.

A aceleração do ritmo de trabalho é uma constante, percebida por homens e mulheres indistintamente e parece ser este um "efeito" da implantação das técnicas japonesas detectado não apenas no Brasil. Volkoff (1993) apura, a partir de pesquisas realizadas na França, que a adoção das práticas japonesas tem conduzido a uma reorganização das imposições temporais, tanto intensificando o ritmo de trabalho, como adotando horários de trabalho atípicos como alongamentos ou quebras nos horários de trabalho anteriormente estabelecidos, trabalho noturno etc.

Dessa forma, ao mesmo tempo em que se conservaram as imposições tradicionais do tipo de trabalho em linha, que afeta principalmente as mulheres, desenvolveram-se novos ritmos impostos, ligados à flutuação da demanda. Entre 1984 e 1991 verificou-se, na França, que os assalariados se ressentiam cada vez mais do sofrimento físico, mental e psicológico, em função da degradação das condições de trabalho (Gollac e Volkoff 1996).

Segundo os mesmos autores, são várias as pressões sofridas pelos trabalhadores expostos às novas técnicas de produção e controle. Em primeiro lugar, o fato de elas serem poupadoras de mão-de-obra é decisivo para todos: a possibilidade de ser o próximo a ser demitido é grande. Aqui, a incerteza quanto ao futuro está imbricada à necessidade vital de cumprir metas de produção em tempos cada vez menores, impostos pelas novas máquinas informatizadas ou pelos dispositivos eletrônicos incorporados a antigas máquinas. Também o aumento da vigilância ligada ao funcionamento da máquinas e às normas de produção que passam a ser cada vez mais rigidamente determinadas, impossibilita os empregados de fazer variar os tempos que lhes são fixados, exigindo um estado de alerta constante. Pressões também advêm da dificuldade de conciliar exigências de qualidade e pressões no ritmo de trabalho, principalmente quando o controle de qualidade é transferido para o operador. A responsabilidade - transferida ao trabalhador - de manter o ritmo de produção à montante e à jusante, é situação que, por si só, provoca, além do que, muitas vezes, incentiva a adoção de posturas físicas desconfortáveis, não adequadas. 
As falas dos entrevistados confirmam essas constatações:

- O ritmo é forte e cansativo, aumentou devido ao aumento da produção e aos novos dispositivos nas máquinas.

- Hoje há menos tempos mortos, faço de tudo, preparo máquina, verifico peças, controlo Kanban e tem que produzir... tem havido problemas de LER.

- O stress acontece porque o ritmo é grande e o chefe fica de olho. Se não fizer o mínimo voce fica marcada.

A intensificação dos ritmos de trabalho teve como mola propulsora, no caso das empresas pesquisadas, a facilitação tecnológica, a qual aumenta o grau de facilidade na execução do trabalho:

- Ficou mais fácil operar máquina com o sensor.

- Equipamentos mais fáceis de trabalhar, tarefas mais fáceis.

- Hoje está mais mecanizado e isso facilita a nossa atividade.

- Hoje as máquinas são computadorizadas, inteligentes, são mais fáceis de operar... já vêm programadas, é só escolher o programa.

Portanto, ao mesmo tempo em que novas tecnologias aumentam a segurança do trabalhador, aliviam certos esforços físicos e facilitam as tarefas, também trazem novas imposições temporais, aceleram o trabalho, aumentando as pressões mentais e físicas.

\section{As mudanças organizacionais e a comunicação}

Entre as alterações de cunho organizacional, a eliminação de vários escalões de supervisão e chefias intermediárias ocorreu em todas as empresas e é percebida de forma positiva pelos trabalhadores de ambos os sexos:

- A relação com a chefia melhorou porque diminuiu o número de chefes.

Todos indicaram melhoria no convívio entre os diversos níveis hierárquicos, o que acarretou ganhos em agilidade e descomplicação na comunicação dos operadores e profissionais do chão de fábrica com engenheiros, chefias e gerência: 
- Cada chefe tem seu setor e não interfere no trabalho ou na área dos outros; então, é menos confuso, não tem dois chefes na mesma área dando ordens diferentes.

Apenas os homens se referiram a melhorias objetivas no andamento do trabalho cotidiano:

- O set-up está muito mais rápido, leva menos tempo para começar outro kanban. (prensista)

- Melhorou o andamento do trabalho porque hoje se passa o problema diretamente para o engenheiro evitando distorções dos chefes. (fresador-ferramenteiro)

As inovações organizacionais, entretanto, podem produzir meIhorias no relacionamento entre os trabalhadores até certo nível como, por exemplo, a diminuição de atritos naturais em ambientes com muita gente:

- Aumentou o nível de união entre os operadores porque agora são menos pessoas. (prensista)

- Como a turma diminuiu, também diminui o nível de atrito com as colegas... (montadora)

Os padrões de relacionamento têm raízes diversas, entre as quais destacamos as baseadas nas relações de gênero. Como sugere Kérgoat (1989), o modo mais habitual das mulheres se relacionarem umas com as outras no ambiente fabril é através da reação de forma atomizada, onde o afrontamento ocorre entre cada mulher oposta a todas as outras mulheres de seu grupo de trabalho. O medo, entre elas, está sempre ligado à sua própria individualidade, sem mediação de grupo e, por isso, cada mulher se vê sozinha perante a máquina, o chefe, em oposição a todas as outras mulheres. Os homens, diferentemente, agregam-se em subgrupos (operadores, ferramenteiros, jovens, mais velhos por exemplo) e, apesar dos conflitos, esses subgrupos representam um grau de proteção, ainda que pequeno, contra as arbitrariedades presentes no ambiente de trabalho. Nesse contexto, o terreno para o nascimento da solidariedade parece ser mais propício:

- Gosto de trabalhar aqui pelo relacionamento. (fresador-ferramenteiro)

- Às vezes, falta um pouco de companheirismo entre certas muIheres que trabalham o dia inteiro sem falar com as outras. (montadora) 
- Prefiro trabalhar com homem, entre mulher só tem confusão, briga, uma querendo passar por cima da outra. (operadora de máquina)

A questão da multifuncionalidade

Reiteradas pesquisas têm constatado que a multifuncionalidade - entendida como a situação em que um mesmo profissional executa diversas funções relativas à sua área de trabalho -, na prática, vem sendo operacionalizada de outro modo.

As falas dos entrevistados demonstram que, nas empresas da amostra, a situação é semelhante. Dentre elas, duas alteraram a titulação dos cargos dos trabalhadores para "operador(a) multifuncional", porém, tanto nessas como na outra empresa de autopeças onde não ocorreu alteração na denominação dos cargos, a descrição do conteúdo do trabaIho feita pelos entrevistados sugere que o que ocorreu foi um acréscimo de tarefas e operações correlatas às desempenhadas anteriormente, tanto no caso dos homens como no das mulheres.

Conforme já comentado anteriormente, algumas das moças acrescentaram às tarefas manuais tradicionais, o manuseio de máquinas instaladas nas próprias linhas de montagem. Uma outra, além disso, passou a ter algum controle sobre a máquina que operava, a preencher cartão de montagem de válvulas e a confirmar o desenho no setor de desenho. O prensista, por sua vez, passou a executar tarefas de preparador de máquina, inspetor de produto etc.

A percepção das mudanças ocorridas no trabalho cotidiano, entretanto, são diversas, conforme o sexo do entrevistado.

O rapaz que trabalhava nas prensas de uma seção de estamparia da indústria mecânica identifica alterações significativas no seu trabalho cotidiano. Em primeiro lugar, percebe que, com a alteração do título do cargo que ocupa, de "prensista" para "operador multifuncional", o cotidiano de trabalho também se alterou. Assumiu tarefas antes executadas por trabalhadores que foram dispensados ou transferidos, a partir das modificações que foram e ainda estão sendo introduzidas na empresa onde trabalha:

- Além de prensista, assumi funções de ajudante, preparador, inspetor de qualidade, apontador. Também faço um pouco o 
papel de mecânico, já que executo a manutenção preventiva da máquina.

Esse trabalhador percebe que a multifuncionalidade acrescentou, enriqueceu, "levando o pessoal a se aprimorar", na medida em que, hoje, outras tarefas estão sob sua responsabilidade. Entretanto, a realização de um maior número de tarefas não teve contrapartida em remuneração. Ao final, deixa claro que as pressões físicas no trabalho se acentuaram, até porque a empresa não se equipou adequadamente para aliviá-las:

- A empresa tinha que manter só o pessoal essencial e fazer esse pessoal se aprimorar, mas junto com a multifuncionalidade deveria haver uma redistribuição de ganhos, deveria haver compra de equipamentos para ajudar, por exemplo, a carregar uma caixa pesada aliviando esse esforço da gente, evitando problemas de cansaço, tendinite. Por muita pressão, as pessoas se estafam.

O outro trabalhador parece estar passando por uma situação inversa. Em primeiro lugar, a empresa não conseguiu implantar a polivalência por pressões do sindicato. Depois, como parte da atividade da ferramentaria foi terceirizada, suas tarefas também diminuíram e o ritmo de trabalho amainou:

- Quando entrei, construía ferramentas, fazia moldes e estampas. Hoje, só faço moldes e estampas porque a construção de ferramentas foi terceirizada.

Para as mulheres, a multifuncionalidade também se expressou concretamente como acréscimo de trabalho, operações. Ainda assim, a situação atual parece ser percebida, por algumas delas, sem diferenciação em relação à época anterior à introdução das mudanças. Uma dessas mulheres, apesar de ter passado de montadora de linha tradicional a operadora de duas máquinas e de, nessa transição, ter seu cargo redefinido para "operadora multifuncional", não vê mudanças:

- Não mudou quase nada, só o nome da função... acho que multifuncional deve ser isso: que a gente faz tudo o que tem para fazer"

Para outras duas entrevistadas, a multifuncionalidade significou continuar fazendo tudo o que faziam antes - inclusive substituir a colega que fica ao lado na linha ou a que opera a máquina ao lado, o que pode ser entendido como rotação de tarefas - e, em alguns casos, operar mais uma máquina: 
- Trabalho em outro posto além dos terminais... quando estou no terminal, uma moça fica nas tampas, depois mudamos...

- Antes fazia várias operações na linha de montagem tradicional, hoje opero uma máquina, mas, também, faço o serviço de outras pessoas na área, quando alguém falta.

- De repente, mudaram o nome para multifuncional, me disseram que eu ia fazer todo o serviço da minha área. Quando necessário, passo da máquina para a linha tradicional.

Perceber de forma diferenciada as alterações no trabalho cotidiano pode estar refletindo o fato de que, conforme interpretam alguns estudiosos, a multifuncionalidade se apresenta diferente para homens e mulheres. Para muitos dos homens, o processo de reorganização do trabalho - no qual se insere a questão da multifuncionalidade - conduziria a um enriquecimento, incorporando tarefas como controle de qualidade, manutenção preventiva etc. Já para as mulheres, a integração das tarefas, ao contrário, tenderia a mantê-las no mesmo patamar de qualificação, uma vez que as operações/tarefas integradas seriam destituídas de conteúdo e da mesma natureza das anteriormente desempenhadas.

Contudo, é provável, também, que as relações de gênero estejam na base da percepção diferenciada da multifuncionalidade. Acostumadas à flexibilidade para poderem se desincumbir da variada gama de tarefas que Ihes são atribuídas tradicionalmente no âmbito doméstico, é possível que as mulheres encarem como "natural" o cumprimento simultâneo de várias tarefas atribuídas ao seu posto de trabalho na fábrica, dando pouca atenção ao fato de terem sido acrescentadas mais algumas, mesmo que algumas dessas tarefas incluam a operação de mais uma máquina e o controle de seu padrão de funcionamento, a checagem dos desenhos do produto que a máquina reproduzirá no setor de arquivo etc.

Talvez, por isso, achem que seu trabalho continua o mesmo de antes. Nesse sentido, o fato de encararem como "natural" seu múltiplo desempenho, pode estar impedindo que essas mulheres percebam e avaliem com maior clareza o que, de fato, estão fazendo a mais e de diferente no seu trabalho. Lembre-se aqui que as tão decantadas - e bem utilizadas - habilidades naturais das mulheres não passam de estereótipos profundamente imbricados nas relações de gênero, que imprimem uma desvalorização constante à mulher, como ser feminino e como trabalhadora (Kérgoat 1989). 


\section{As condições de trabalho}

As empresas aqui consideradas parecem ter investido na melhoria das condições físicas de trabalho. O ambiente físico de trabalho nessas empresas parece ter sido reorganizado, para melhor:

- Hoje, há mais limpeza... reorganizaram as máquinas para facilitar a operação.

- Antes havia muita máquina, era apertado. Hoje, ampliaram o prédio, ficou mais organizado o espaço.

A preocupação com a segurança dos empregados também tem sido maior, até em função da atuação firme das Cipas:

- A empresa cuida bem da segurança, a CIPA é boa.

- Antes tinha máquinas que não tinham segurança, hoje tem mais.

- Em relação à segurança, minha máquina é bem equipada... segura.

- Antes não havia protetor de ouvido, óculos e era mais barulhento.

- Em termos de segurança, aumentou muito porque colocaram cortinas óticas nas máquinas para prevenir acidentes, há mapas de riscos, instalaram sistemas para diminuição de ruídos.

Entretanto, segundo os próprios trabalhadores, persistem muitas condições adversas e insalubres (particularmente na indústria mecânica) como ruído, calor, odores e possibilidades de acidentes:

... ruído bastante alto e a ventilação não funciona, tornando o local bastante abafado. (fresador-ferramenteiro)

Dependendo da máquina, a minha, por exemplo, o calor continua.

Muita gente tem problema de audição, mesmo com o protetor de ouvido.

Com a intensificação do ritmo de trabalho tem havido muito problema de saúde, desde estafa, até tendinites e aumento de casos de LER (lesões por esforços repetitivos):

Há partes críticas como a montagem onde há muito problema de LER.

Há muito problema com o trabalho em certas máquinas, muita canseira, aumento de serviço. 
Portanto, parecem ainda existir muitos pontos que trazem danos à saúde do trabalhador nessas empresas, apesar de se ter conseguido alguns avanços. Uma pesquisa mais apurada sobre esta questão poderia indicar se, como ocorre na França (Gollac e Volkoff 1996), ao lado da diminuição do nível de ruído, calor, de riscos de acidentes, também não estaria crescendo a exposição dos trabalhadores a outros fatores como, por exemplo, posturas penosas, carga de peso etc.

\section{Considerações finais}

Os trabalhadores entrevistados avaliam que, após a introdução das modificações no sistema produtivo e na forma de gestão dos recursos humanos, implementadas pelas empresas onde trabalham, houveram ganhos. Mas também revelam, através de seus depoimentos, que passaram a estar sujeitos a maiores pressões mentais e físicas, fato este já relatado na literatura internacional, quando se trata de tentar verificar os efeitos das técnicas japonesas nas condições de trabalho e na saúde do trabalhador.

Nas três empresas onde trabalham, estão presentes o CEP, o JIT externo, principalmente, o JIT interno e o Kanban, as células de produção, os CCQs, em diferentes graus de disseminação. Todas obtiveram certificações de qualidade ISO.

Os ganhos ficaram por conta da introdução de inovações tecnológicas. Nas linhas de montagem, as moças hoje trabalham de forma mais fácil, sem tanto esforço, graças à instalação de dispositivos eletrônicos. Outro fator facilitador foi o investimento que essas empresas fizeram no ambiente físico da fábrica (aumentando as instalações, dando mais atenção à limpeza, instalando equipamentos para diminuição de ruídos, ventiladores e exaustores, reorganizando efetivamente o espaço através da diminuição do número de máquinas, ou rearranjando o lay-out) e na questão da segurança. Nesse aspecto, as Cipas tiveram grande influência, pois os riscos de acidente diminuíram através da instalação de dispositivos de segurança nas máquinas e da disseminação de equipamentos de proteção entre os empregados.

Outro aspecto que os trabalhadores avaliam como positivo foi a eliminação de vários escalões de supervisão e chefias intermediárias. Essa modificação organizacional levou a uma melhoria no convívio entre os diversos níveis hierárquicos, acarretando maior agilidade e descomplicação na comunicação dos operadores e profissionais do 
chão-de-fábrica com engenheiros, chefias e gerências, além de melhorar o andamento do próprio trabalho.

Entretanto, todos os entrevistados percebem que as pressões mentais e físicas aumentaram. Essa situação é decorrência de vários fatores. Em primeiro lugar, está a aceleração do ritmo de trabalho. Ao introduzir dispositivos eletrônicos nas máquinas, o trabalho fica mais fácil e seguro, mas, em contrapartida, fica também mais rápido. As metas de produção aumentam, é imposto o desempenho de tarefas adicionais e tudo isso exige maior concentração e atenção do trabalhador. As práticas de autocontrole como o CEP e de controle grupal, como os CCQs, ajudam a aumentar ainda mais o grau de responsabilidade que passa a ser exigido do trabalhador, gerando, muitas vezes, estafa mental. Além disso, para seguir a cadência imposta pelas máquinas ou pelos colegas de linha de montagem, o trabalhador nem sempre pode escolher a postura física que é melhor, provocando cansaço físico. Os casos de tendinite e de LER vêm se multiplicando, principalmente nas áreas críticas, como as de montagem, onde predominam as mulheres.

Outro fator gerador de estresse e de certa insatisfação é a forma como as empresas em questão estão introduzindo o conceito de multifuncionalidade. Na prática, aquela noção se transformou em "multitarefa", ou seja, acrescentar um novo rol de tarefas às que o operador já fazia. Trata-se, na maioria das vezes, de uma redistribuição de funções eliminadas do processo, para os empregados que ainda permanecem empregados.

A percepção e a avaliação da implantação da multifuncionalidade parecem ser diferentes conforme o entrevistado seja homem ou mulher. Os homens percebem que essa é uma tendência geral nas empresas, sentem ser possível algum aprimoramento profissional e, quem sabe, uma promoção futura. Mas consideram, também, que não tiveram nenhuma retribuição financeira por estarem executando um maior número de tarefas, o que lhes tem provocado sobrecarga de trabalho e cansaço. As mulheres não percebem grandes alterações no seu trabalho atual quando comparado ao que faziam antes de as empresas instituírem o conceito de multifuncionalidade, ainda que, concretamente, alterações tenham ocorrido.

É provável que essas diferenças de percepção e avaliação tenham como base a conhecida segmentação do trabalho entre os sexos na fábrica, cabendo às mulheres tarefas repetitivas e mais simples quando comparadas às executadas por uma significativa parcela dos homens, conhecidos como "profissionais". Para elas, a implantação da multifuncio- 
nalidade promoveria alguma integração de tarefas daquela mesma natureza, enquanto para o segmento dos "profissionais", a tendência seria um maior enriquecimento do trabalho, incorporando tarefas de controle e manutenção, de gerenciamento do próprio trabalho.

É provável, também, que as relações de gênero estejam na base da percepção diferenciada da multifuncionalidade pelos dois sexos. No caso das mulheres, apesar de descreverem alterações concretas no seu cotidiano de trabalho e de identificarem um rol de novas tarefas acrescentadas às que executavam antes, no nível do discurso, concluem que a introdução da multifuncionalidade alterou tão-somente o nome de seus cargos.

É possível que, ao fazerem tal afirmação, as mulheres estejam tomando como referência seu desempenho no âmbito doméstico, onde, secularmente, foram acostumadas ao cumprimento das várias tarefas simultâneas que Ihes são atribuídas, às quais sempre podem ser acrescentadas mais algumas. O fato de encararem seu desempenho como "natural", pode estar impedindo essas mulheres de perceberem e avaliarem, com maior consciência, as implicações da multifuncionalidade no seu trabalho na fábrica.

Notas

1. Essas entrevistas fazem parte do esforço coletivo de pesquisa realizado pela equipe do projeto "Reestruturação Produtiva e Qualificação", realizado no setor automotivo situado na Grande São Paulo, coordenado pela professora Márcia de Paula Leite, entre 1996 e 1997.

\section{Productive restructuring in the automotive industry in São \\ Paulo: Worker's perceptions of changes in work condition}

ABSTRACT: Workers indicate that changes in the production system and in management techniques in three auto parts firms have brought some improvements but also resulted in greater mental and physical pressure. Improvements have arisen mainly with the introduction of technological innovations which have eased and simplified work. Increased pressure has derived from the intensification of the pace of work, which has resulted in increased cases of Repetitive Strain Injury (RSI) and the introduction of polyvalence. Male and female workers evaluated the effects of polyvalence in different ways. When women affirm that "nothing has changed" in their work with the 
introduction of polyvalence, it is possible that they are using the domestic sphere as their point of reference, where it is "natural" for them to perform a variety of activities simultaneously, to which additional tasks can always be added.

\section{Bibliografia}

BERGGREN, C. "Point/Counterpoint: Nummi vs. Udevalla", Sloan Management Review, Repreint Series, Winter, no 2, 1994, vol. 35.

BRESCIANI, L.P. "Os desejos e o limite: Reestruturação industrial e ação sindical no complexo automotivo brasileiro". In: Leite, M. (org.). O trabalho em movimento. Campinas, Papirus, 1997.

BRUSCO, S. "The Emilian model; produtive decentralisation and social integration”. Cambridge Journal of Economics, UK, no 6, 1982.

GOLLAC, M. e VOLKOFF, S. "Citius, Altius, Fortius - l'intensification du travail", Reviste Actes de la Recherche en Sciences Sociales, № 114, França, setembro 1996.

HARVEY, D. "Condição pós moderna - uma pesquisa sobre as origens da mudança cultural”, 6aㅡ ed.. São Paulo, Loyola, 1996.

HIRATA, H. Apresentação. In: Hirata, H. (org.). Sobre o modelo japonês. São Paulo, Edusp/ACBJ, 1993.

JURGENS, U. "Lean-production and co-determination: The German experience", In: Babson, S. (edit.). Lean-work - empowerment and exploitation in the global auto industry, Detroit. Wayne State University Press, 1995.

KÉRGOAT, D. "Lutes ouvrières et rapports sociaux de sexe: De la construction du sujet colletif dans l'univers de travail ouvrier". Seminário internacional: Políticas de gestão, relações de trabaIho e produção simbólica, São Paulo, agosto1989.

MARX, ROBERTO. "Organização do trabalho na indústria automobilística sueca”. In: São Paulo em Perspectiva no 1, vol. 8, Fundação Seade, São Paulo, 1994.

POSTHUMA, A.C. "Técnicas japonesas de organização nas empresas de autopeças no Brasil”. In: Araújo Castro, N. (org.). A máquina e o equilibrista - inovações na indústria automobilística brasileira, São Paulo, Paz e Terra, 1995. 
REYNAUD, J.D. "O modelo e seu uso". In: Hirata, H. (org.). Sobre o modelo japonês. São Paulo, Edusp/ACBJ, 1993.

SALERNO, M. "Modelo japonês, trabalho brasileiro", In: Hirata, H. (org.). Sobre o modelo japonês. São Paulo, Edusp/ACBJ, 1993.

SCHMITZS, H. e MUSYCK, B. "Industrial districts ineurope: Policy lessons for developing countries?”. IDS discussion Papers, UK, № 324, abril 1993.

SOUZA-LOBO. "A classe operária tem dois sexos - trabalho, dominação e resistência”. São Paulo, Secr. Municipal de Cultura/ Brasiliense, 1991.

VOLKOFF, S. "O tempo, a saúde, a seleção - três questões relativas ao modelo japonês". In: Hirata, H. (org.). Sobre o modelo japonês. São Paulo, Edusp/ACBJ, 1993. 